\title{
Intraorganellar acidification by V-ATPases: a target in cell proliferation and cancer therapy
}

Agustín Hernández*, Gloria Serrano, Rosana Herrera-Palau, José R. Pérez-Castiñeira, and Aurelio Serrano

Instituto de Bioquímica Vegetal y Fotosíntesis, CSIC-Universidad de Sevilla, Avda. Américo Vespucio 49, 41092 Seville, Spain.

* to whom correspondence should be addressed at IBVF-CSIC, Avda. Americo Vespucio 49, 41092 Seville, Spain. Phone: +34 954 489500. Fax +34 954 460065. E-mail: agustin.hernandez@,ibvf.csic.es

Keywords: V-ATPase, Bafilomycin, Chondropsin, Concanamycin and Salicylihalamide.

Running title: V-ATPase as a target in cancer chemotherapy. 
Abstract: V-ATPases are multicomponent proton pumps involved in the acidification of single membrane intracellular compartments such as endosomes and lysosomes. They couple the hydrolysis of ATP to the translocation of one to two protons across the membrane. Acidification of the lumen of single membrane organelles is a necessary factor for the correct traffic of membranes and cargo to and from the different internal compartments of a cell. Also, V-ATPases are involved in regulation of $\mathrm{pH}$ at the cytosol and, possibly, extracellular milieu. The inhibition of V-ATPases has been shown to induce apoptosis and cell cycle arrest in tumour cells and, therefore, chemicals that behave as inhibitors of this kind of proton pumps have been proposed as putative treatment agents against cancer. The present review will summarize the major types of V-ATPase inhibitors and their mechanisms of action and put them in relation to the patents registered so far for the treatment of cancer. 


\section{INTRODUCTION}

Transport of cargo and membranes from the endoplasmic reticulum to their final destinations is vital for eukaryotic cells. The major players in this flux of vesicles and proteins are the endoplasmic reticulum (ER, the site were both proteins and lipids are synthesized), the Golgi apparatus, early and late endosomes, other single-membrane vesicular organelles derived from these, such as peroxisomes and exocytic vesicles, and the lysosome. The latter, together with the plasma membrane, can roughly be considered as terminal destinations. Nevertheless, membrane and cargo can flow both ways, for example, from ER to the lysosome (anterograde) or from the plasma membrane to the ER (retrograde). The detailed mechanisms and players involved in fission, fusion and transport of vesicles are an active field of research. However, one of the requirements known for a correct function of the endo/exocytic pathway is the presence of an electrochemical gradient across the membranes of these organelles, mostly in the form of a proton gradient $[1,2]$. The extent of this gradient is different in each compartment (Fig. 1). While ER remains at near-neutral pH and shows no remarkable difference with respect to the cytosol, lysosomes can hold a 3-pH unit gradient [2]. Other compartments show $\mathrm{pH}$ values somewhere in between these two extremes. As a rule of thumb, the extent of lumenal acidification for vesicular organelles is greater the farther they are from the ER and the closer they are to a terminal destination (plasma membrane or lysosome). Indeed, to think of these $\mathrm{pH}$ gradients only as part of the vesicle transport mechanism is an oversimplification. The acidification of the vesicular lumens are also necessary for the numerous functions of these organelles. For example, glycosylation of proteins in the Golgi apparatus is impaired if the $\mathrm{pH}$ gradient is abolished in this organelle $[3,4]$. The generation of these positiveinside proton gradients is carried out by a class of proton pumping ATPases, usually called VATPases, in concert with counter ion conductance driven by channels and other transporters. It is also balanced by the intrinsic proton permeability of the membrane and the activity of proton consuming transporters such as $\mathrm{H}^{+}$antiporters [2]. V-ATPases get their name because they were first 
described in vacuoles (the plant and fungal equivalent of the animal lysosome), but later they were found across the range of single-membrane organelles in all eukaryote organisms. Mitochondria and chloroplasts do not bear this kind of proton pumps but the closely related $\mathrm{F}_{0} \mathrm{~F}_{1}$ type. At any rate, $\mathrm{V}$ ATPases are not exclusive of the endo/exocytic system. They also exist and fulfil physiologically important functions at the plasma membrane of certain mammalian cell types, such as those at the vas deferens and osteocytes. Diseases like osteoporosis owe a great deal to plasma membrane VATPase dysfunction. In cancer they have been suggested to influence metastatic potential by providing an acidic extracellular environment that would ease protease action on the extracellular matrix [5]. Although it is a promising hypothesis that deserves future attention, the actual importance of V-ATPase-mediated extracellular acidification, as opposed to improvement of other intracellular organelle functions, has not been sufficiently addressed yet. Conversely, their effect on drug resistance and proliferation through acidification of endocellular compartments and cytosolic $\mathrm{pH}$ homeostasis seems, comparatively, well established. We will thus concentrate on V-ATPases and their inhibitors as modulators of lumenal and cytosolic $\mathrm{pH}$ in cancer.

\section{V-ATPASE STRUCTURE AND TRANSPORT MECHANISM}

V-type ATPases are very complex biochemical machines. A general model is depicted in Fig. 2. They are multimeric proteins consisting of two main domains $\left(\mathrm{V}_{0}\right.$ and $\left.\mathrm{V}_{1}\right)$. From extensive experimentation on the yeast enzyme it is now known that the membrane-embedded domain $\left(\mathrm{V}_{0}\right)$ is composed by 9 polypeptides: single copies of a, $c^{\prime}, c^{\prime \prime} d$ and e, and four copies of $c$. On its turn, the hydrophilic $\mathrm{V}_{1}$ domain is composed by 12 polypeptides: three $\mathrm{A}$, three $\mathrm{B}$, single copies of $\mathrm{C}, \mathrm{D}, \mathrm{E}, \mathrm{F}$ and $\mathrm{H}$ and two copies of $\mathrm{G}$. In mammals, subunit $\mathrm{c}^{\prime}$ is substituted by another $\mathrm{c}$ subunit and an additional regulatory subunit (Ac45) is present. However, these differences do not alter significantly the catalytic mechanism or the general model for the mammalian enzyme. Proton pumping is achieved by a rotary mechanism similar to that observed in the closely related $\mathrm{F}_{0} \mathrm{~F}_{1}$ proton pump in 
mitochondria. Subunits A harbour catalytic domains that, by hydrolysing ATP, provide torque to the $\mathrm{V}_{1}$ domain that is transmitted to the $\mathrm{V}_{0}$ domain by stalk subunits $\mathrm{D}, \mathrm{F}$ and subunit $\mathrm{d}$ at the $\mathrm{V}_{0}$ domain. This makes the membrane ring complex composed of subunits $\mathrm{c}_{4}, \mathrm{c}^{\prime}, \mathrm{c}^{\prime \prime}$ to rotate while subunit a and the $A_{3} B_{3}$ complex remain static. This movement provides a path for proton transport through two hemi-channels present in subunit a. One proton from the cytosol enters the first hemichannel and it is complexed to a protonable glutamate residue on subunits $\mathrm{c}, \mathrm{c}^{\prime}$ or $\mathrm{c}^{\prime \prime}$. The cation remains associated to its ring subunit until sector $\mathrm{V}_{0}$ makes a new full turn; the stability of the cation-protein interaction is enhanced due to its direct contact with a non-polar environment such as the lipid milieu [6]. When a protonated c-like subunit in the rotor reaches again subunit a, the protonated residue enters in contact with the second polar hemi-channel and the cation is released into the lumen. Subunits B, albeit carrying ATP binding sites, are not capable of hydrolysis and are considered regulatory [6].

In vivo modulation of V-ATPase activity can be achieved by several mechanisms. $\mathrm{V}_{1}$ domains can exist as both soluble cytosolic complexes or bound to $V_{0}$ domains. Since neither free $V_{0}$ nor $V_{1}$ domains are capable of proton transport or ATP hydrolysis, respectively, assembly and disassembly of $V_{1}$ from $V_{0}$ is believed to be a mechanism providing fast regulation of pump activity, especially in situations of dynamic glucose availability [1, 7]. Modulation of its $\mathrm{H}^{+} / \mathrm{ATP}$ transport stoichiometry is another mechanism of regulation. Subunit a holds both hemi-channels on its $C$ terminus and can produce V-ATPases with varying stoichiometry, depending on the integration of different isoforms of this polypeptide into the mature protein complex. For example, in yeast, VATPases bearing isoform Stv1p shows a stoichiometry of 1 proton per hydrolysed ATP, whereas if the same enzyme carries isoform Vph1p that parameter increases to $2 \mathrm{H}^{+} / \mathrm{ATP}$. Also, other subunits may, in theory, alter the ratio of transported protons per ATP as seen in mutagenesis studies over subunits $\mathrm{A}, \mathrm{C}$ or $\mathrm{d}[8]$. In mouse and humans there are four a subunit genes with at least three transcript variants for a1, in the case of humans. However, although in mammals it seems plausible that a similar mechanism applies, no detailed information is available as if it actually occurs. 
Phosphorylation of the holoenzyme has also been reported. In insect cells, it was first described that $\mathrm{C}$ subunit was phosphorylated by protein kinase $\mathrm{A}$ and that this was instrumental for correct $\mathrm{V}_{1} / \mathrm{V}_{0}$ assembly [9]. Shortly after, yeast Dbf2p protein kinase was shown to phosphorylate both A and B subunits, moreover $d b f 2 \Delta$ deletion strains were unable to acidify their vacuoles [10]. In mammals, phosphorylation of epididymides V-ATPase by PKA has also been observed [11]. Yet another mechanism of transport regulation is the control of the number of pumps resident in an organelle. This regulation has been clearly observed for the plasma-membrane resident V-ATPase, where its number is affected by the rate of sequestration into recycling endosomes [8]. Indeed, changes in exo/endocytic flux dynamics could provide a possible explanation to the increased number of VATPases found at the plasma membrane of malignant tumor cells. However, to date, no indications exist as to whether a similar mechanism is at work in other membranes.

\section{IMPORTANCE OF V-ATPASES FOR A CANCER CELL}

A tumour cell's fast pace of growth is supported by an accelerated metabolism. This fuels the synthesis of new cellular components, such as proteins or lipids, that need to be transported to their final destinations. In this context, the importance of V-ATPases for tumor cell can be easily understood. Despite this, V-ATPases do not seem to be greatly overexpressed in neoplastic cells, as opposed to many other important proteins in rapidly dividing cells, such as mitosis-related proteins [12]. The subunit/gene complexity of these proton pumps probably makes the overexpression of all of them in a coordinated way a phenomenon very unlikely to occur. However, increased expression of several isoforms have been reported. For example, it has been shown that ATP6V1C1 human gene (encoding subunit $\mathrm{C}$ ) is overexpressed in oral squamous carcinoma cells and that this may promote a greater degree of $\mathrm{V}_{1} \mathrm{~V}_{0}$ assembly than in normal tissue (Otero-Rey 2008). Similarly, different subunit genes have been found to be overexpressed in drug-resistant cell lines, including ATP6L (ATP6V0C, subunit c) in the case of cisplatin resistance (Torigoe, 2002). Moreover, it has 
been demonstrated that overexpression of proteolipid c leads to increased invasiveness in stable transfectants [13]. One of the consequences of this all is that tumour cells depend more heavily on the activity of V-ATPases than normal cells. This is exemplified by the well known apoptosis induction capability of V-ATPase inhibitors in tumour cells [14, 15]. It has been proposed that the acidic environment within endosomes helps dissociation of ligands from their receptors, helping thus the recycling of the later back to the plasma membrane [16]. Alternatively, inhibition of the VATPase would lead to endo/exocytic malfunction that, in turn, should cause receptors for growth factors such as EGFR to remain associated to their ligands in endosomes and not properly degraded [17]. In addition, alkalinization of intracellular vesicular compartments would lead to protein misorting. In yeast models, plasma membrane proteins have been observed to mislocalize in VATPase mutants [18]. In mammals, glycosyltransferases at the Golgi apparatus have been proven to be sensitive to the lumenal ion composition. In particular, these enzymes are rapidly missorted to endosomes if Golgi $\mathrm{pH}$ is affected by merely $0.4 \mathrm{pH}$ units [3, 4]. This same phenomenon has been observed for secreted proteins such as chromogranin A [19] and viral VSV-G [20], although, in the later case, it might also be connected to the already mentioned redistribution of glycosyltransferases.

Tumor cells live in a harsh microenvironment. Hypoxic conditions and rapid growth rates make these cells to rely on glycolysis and lactic acid fermentation to obtain the energy they need, rather than on respiration; this is the so-called Warburg Effect [21]. This anaerobic metabolism has the downturn of producing great amounts of protons that need to be neutralized from the cytosol. At the same time, deficient perfusion of solid tumors leads to low extracellular $\mathrm{pH}$ that, in turn can contribute to select cells able to thrive in such an environment because they can efficiently drive away protons from their cytoplasms. These cells could be more effective sequestering cytosolic protons into intracellular vesicular compartments or could be expelling them back to the intercellular milieu. In all of these cases, V-ATPases play an important role. It has been proven that V-ATPases are present at the plasma membrane of tumor cells and that their abundance correlates 
with proliferation and metastatic potential [5]. However, it is still unclear if many of the phenotypes observed in these cells are caused by V-ATPases at the plasma membrane or due to concomitant increased endo/exocytic rates. Cathepsins, matrix metalloproteases and other proteases involved in metastasis, have been invoked as the beneficiaries of increased plasma membrane proton extrusion and acidification of the extracellular medium since they need an acidic environment to loosen the extracellular protein matrix. However, bearing in mind that there are several other factors involved, it is still difficult to ascertain to which extent plasma membrane V-ATPases contribute to extracellular acidification. Moreover, many of these proteases are intracellular in normal cells but in neoplastic ones become overexpressed and secreted [22]. This differential location can be greatly influenced by enhanced activity of endocellular V-ATPases which would make transit of the overproduced proteases more speedy and become secreted, as a side effect. At any rate, more work is needed to shed light to the influence of plasma membrane V-ATPases on extracellular acidification. Under the mentioned growth conditions, internal $\mathrm{pH}$ homeostasis is of paramount importance: on the one hand, protons are rapidly produced in glycolysis-lactic acid fermentation and, on the other, they also tend to invade the cytosol from the acidic extracellular medium. In this context, a robust V-ATPase activity, either at the plasma membrane or on intracellular compartments can represent a clear proliferative advantage by transporting protons away from the cytosol. Moreover, it is known that acidic conditions at the cytosol promote apoptosis while a mildly alkaline $\mathrm{pH}$ at the cytoplasm is a requisite for proliferation [23]. At the same time, a neutral to mildly alkaline cytosol and the establishment of well formed $\mathrm{pH}$ gradients across intracellular vesicular compartments such as the lysosome is vital for drug resistance since many drugs are cationic. This means that alkaline cytosols provide a barrier against drug diffusion across the plasma membrane and, once inside, drugs tend to get sequestered in the lumen of acidic intracellular compartments $[24,25]$. Remarkably, tumour cells that are able to maintain greater $\mathrm{pH}$ gradients in these compartments are more drug-resistant than normal ones [26, 27]. 


\section{INHIBITORS OF V-ATPASES}

Due to the great importance of V-ATPases in many physiological and pathological situations, including cancer, there has been an active search for specific inhibitors that could be used both in the clinic and in research. As a result, nowadays there are a large amount of different inhibitors against V-ATPases that fall into different categories, although they tend to share some common characteristics. On the whole, with the exception of the indoles and azaindoles, all inhibitors may be considered polyketides, i.e. large structures that are putatively synthesized in a manner akin to the first steps of fatty acid synthesis (Claisen condensation of propionyl or acetyl residues). Futhermore, many fall in the category of macrolides (structures with large lactone rings). This complexity in the structures has made the search for simpler, easier to synthesize compounds and active field of research but, to date, successes have been few.

The effect of treatment of tumour cells with V-ATPase inhibitors has been majoritarily analysed using the classical macrolide inhibitors bafilomycin A and concanamycin A; however, most of the effects seen have been confirmed with other types of inhibitors. As expected, inhibition of proton transport by V-ATPases results in alkalinization of intracellular vesicular compartments and acidification of the cytosol $[28,29]$. In B cell lymphoma lines, this process has been observed to be concomitant to an increase in reactive oxigen species that, in turn, induced cell death [29]. In these conditions, sequestration of hydrogen peroxide with $\mathrm{N}$-acetylcisteine inhibited cell death but inhibition of caspase activity was ineffective. In all reports where cell death details have been investigated so far, apoptosis is the described mechanism ensued from inhibition of V-ATPases [15, 30-33], albeit not all types of compounds have been studied as to their mode of cell death induction. Thus, there exist no data yet for archazolids and indoles, and very few in the case of benzolactone enamides. Nevertheless, with the exceptions noted above, the intrinsic pathway of apoptosis is involved in this process through mitochondrial depolarization and liberation of cytochrome $\mathrm{c}$ to the cytosol [15, 29, 34, 35]. Furthermore, caspases are central for V-ATPase inhibitor-induced apoptosis 
$[15,35,36]$, although in B-cell tumor lines it has been reported that bafilomycin A induces caspaseindependent cell death [29]. On the other hand, in EGFR overexpressing cancer cell lines, the extrinsic pathway of apoptosis has also been reported to play a decisive role through Fas/FasL in concanamycin B-induced cell death [14].

Cell cycle arrest is also a common outcome of V-ATPase inhibition. Cells tend to arrest in G1 due to increased expression of the $\mathrm{G} 1 / \mathrm{M}$ transition inhibitor p21 [28, 30, 37, 38], although the exact mechanisms to this end are still somewhat obscure. In HT-29 colon cancer cells, it was observed that intracellular compartment alkalinization triggered-p21 induction was partially p53 independent, although p53 was stabilised as a response [28]. Alternatively, G1 arrest may be related to inhibition of the degradation of hipoxia-inducible factor $1 \alpha$ (HIF-1 $\alpha)$ [38]; HIF-1 $\alpha$ is a transcription factor responsible for the induction of p21 under conditions of hypoxia and is kept at low levels in oxygenic conditions by degradation via the proteasome [39]. The link between HIF-1 $\alpha$ degradation and V-ATPase inhibition is yet unknown.

\section{PLECOMACROLIDES: BAFILOMYCINS AND CONCANAMYCINS}

Bafilomycin A was the first reported specific inhibitor of V-ATPases [40], closely followed by concanamycin A [41]. Both compounds are very similar, consisting of large macrocyclic lactone rings, which place them in the macrolide group, and are generally referred to as plecomacrolides. In nature, they can be isolated from several species of Streptomyces bacteria when grown as a mycelium [42]. General structures of bafilomycin A and concanamycin A are shown in Fig. 3. It took more than ten years to ascertain the binding site of these compounds on the V-ATPase complex, although it was clear that they bound somewhere in the $\mathrm{V}_{0}$ domain. Indeed, early suspicions of binding to subunit a [43] have been confirmed recently [44], thus explaining some details of their effect. However, it is now well established that the major inhibitory mechanism of plecomacrolides is another: these compounds bind to the c proteolipid subunit at a site near or the 
same where DCCD binds, and impair the transport of protons through this peptide [45]. An important consequence of this is that bafilomycins and concanamycins are not selective against VATPases from different origins, since proteolipid $\mathrm{c}$ is the most conserved subunit in V-ATPases. Their $\mathrm{IC}_{50}$ are in the low nanomolar range, which makes this type of compounds extremely potent and useful in research to distinguish between different types of ATPases in a cell. In contrast, P-type ATPases are only inhibited by plecomacrolides in the micromolar range and the closely related $\mathrm{F}_{0} \mathrm{~F}_{1}$ ATPases from mitochondria are not inhibited at all.

Apart from its effect on the proton conductance through $\mathrm{V}_{0}$, there are other possibilities to explain the anticancer capability of plecomacrolides. For example, it has been proposed that bafilomycin A induces the expression of hypoxia-inducible factor $1 \alpha$ (HSF-1 $\alpha$ ) and, concomitantly, p21 [38] leading to cell cycle arrest. Similar results have been reported for the bafilomycin analog hygrolidin [37]. Also, both concanamycin $\mathrm{A}$ and bafilomycin $\mathrm{A}_{1}$ have been shown to induce the production of nitric oxide in RAW 264.7 leukemia cells which, in turn, activated c-Jun N-terminal kinase and NF$\kappa \mathrm{B}$ leading to apoptosis [46]. These effects might be related to a different mode of action recently reported for bafilomycin A: in mitochondria isolated from rat liver, sub-micromolar concentrations of this compound were found to transport potassium leading to swelling and depolarization in a manner resembling that observed for valinomycin; this phenomenon was independent of any effects on the $\mathrm{F}_{0} \mathrm{~F}_{1}$ ATPase [47].

Total synthesis of bafilomycin A was achieved as early as 1997 [48] and that of concanamycin (concanamycin F) in 2001 [49]. Prior to that, their first putative use in cancer chemotherapy was already filed [50]. Since then, several other derivatives and uses have been patented. The importance of intracellular compartment acidification is recognised as central for the anticancer mechanism of plecomacrolides [51] and the usefulness of these compounds to overcome drug resistance [52]. On the other hand, plecomacrolides tend to be unstable in alkaline conditions, which has driven the search for more stable derivatives [53]. Apoptolidin is a peculiar plecomacrolide: its mechanism of action was described as inhibition of the mitochondrial $\mathrm{F}_{0} \mathrm{~F}_{1}$ 
ATPase [54], but in later patent filings it has been suggested that the actual mechanism is similar to that of bafilomycins and concanamycins [55]. However, no data support this hypothesis in peerreviewed journals to date.

BENZOLACTONE ENAMIDES: SALICYLIHALIMIDES, LOBATIMIDES AND APICULARENS

Following the discovery of plecomacrolides, in the late 1990s a series of compounds with strong inhibitory potency against V-ATPases were described within a short period. The first of these (salicylihalimide) was obtained from sponges of the genus Haliclona sp [56], lobatimides where first obtained from the tunicate Aplidium lobatum (hence its name) [57] and apicularens from mixobacteria of the genus Chondromyces [58]. The apparent wide range of organisms used as sources may be misleading, since it is plausible that they are actually synthesized by symbiotic microorganisms [59]. All these compounds share a benzolactone enamide core and show a cytotoxic profile similar to that of plecomacrolides in NCI's 60-Cell screens [59]. Their $\mathrm{IC}_{50} \mathrm{~S}$ also lie in the nanomolar range $[42,60]$. Structures for representative compounds of this class are depicted in Fig 4.

Benzolactone enamides have arisen a great interest due to its selectivity towards animal V-ATPases, as opposed to fungal proton pumps (no studies on plant enzymes have been published so far) [59, 61]. The reason for this selectivity is still unknown, but it is probably related to their different mode of inhibition. In studies using brain V-ATPase, it was shown that salicylilhalimide A bound the $\mathrm{V}_{0}$ domain and that this binding could not be competed by the addition of bafilomycin or concanamycin derivatives $[45,60]$. This was later confirmed for lobatamide [61]. However, a clear picture on the actual subunit and binding site for this type of compounds still has to emerge.

Total synthesis of benzolactone enamides was reported within a few years of their discovery. Thus, salicylihalimide A synthesis was published in the year 2000 [62], followed by lobatamide C [63] 
and apicularen A [64]. Apart from these representatives, this class of compounds have rendered many other chemicals that are not dealt with here but that they share a similar structure and mode of action, such as the cruentarens, the oximidines or the closely related palmerolides. These have been reviewed in more detail elsewhere [42]. Patents have not lagged behind and the application of salicylihalimides and apicularens was filed as early as 2003 [65] and extended later in successive applications $[66,67]$. At times, the potential use of V-ATPase inhibitors as a whole has been found of interest, thus, a patent comprising the use of plecomacrolides or benzolactone enamides (salicylihalimides, lobatamides and oximidines) as sensitizers towards irradiation has also been filed [51]. Lobatamides, together with other benzolactone enamides, have recently received some attention [68]. The last of these compounds to be registered have been the palmerolides, with a patent application in 2008 [69].

\section{OTHER COMPOUNDS: CHONDROPSINS, ARCHAZOLIDS AND INDOLES}

The seek for new V-ATPase inhibitors have rendered new classes of compounds: chondropsins, archazolids and indoles (and their derivatives, the azaindoles). Most of them have been obtained from natural sources but indoles have been obtained from chemical synthesis.

Chondropsins are complex macrolides comprising 33-37 members in a large lactone ring and long polyketide extensions (Fig. 5A). They show potent death inducing capability and were first isolated from marine sponges of the genera Chondropsis and Siliquariaspongia [70, 71]. Later they were described as V-ATPase inhibitors on the basis of their profile on NCI-60 tests and in vitro assays [72]. Surprisingly, these compounds inhibit preferentially fungal V-ATPases, with $\mathrm{IC}_{50} \mathrm{~S}$ in the submicromolar range, rather than mammalian V-ATPases, where they show $\mathrm{IC}_{50}$ s typically in the low micromolar range. Despite this, chondropsins seem to share a similar mode of inhibition with plecomacrolides such as bafilomycins, since mutations affecting bafilomycin sensitivity in the Neurospora crassa enzyme also affect chondropsin inhibition [72]. 
Archazolids are compounds structurally related to the plecomacrolides that also comprise a thiazole ring in a side chain (Fig. 5B). First isolated from the mixobacterium Archangium gephyra [73], archazolid A was shown to inhibit V-ATPases from the tobacco hornworm Manduca sexta $\left(\mathrm{IC}_{50}=20\right.$ $\mathrm{nM}$ ) and acidification of intracellular compartments in mammalian cells [61]. Their mode of inhibition seems to be binding to subunit $\mathrm{c}$ and inhibiting rotation of the holoenzyme, since archazolid A competes with plecomacrolide concanolide A for binding to the $\mathrm{V}_{0}$ domain [61]. Derivatives of archazolides have been produced in order to assess the important residues in the molecule. Substitutions at carbon 7 in these compounds (marked with an asterisk on Fig. 5B) affected severely their effectiveness in mammalian cell assays with comparatively minor effects on their inhibitory capacity in in vitro assays; the ultimate reasons for this are still unknown.

Ten years after the discovery of bafilomycin, Farina and co-workers applied the information obtained so far in structural studies to produce simpler compounds that were able to inhibit VATPases while easy to synthesize $[74,75]$. These compounds are characterized by an indole core with electron-withdrawing residues (usually chloro) at positions 5 and 6 , and an amino substituent after a three- to four-carbon atom spacer. Similarly to plecomacrolides, this kind of inhibitors also bind subunit $\mathrm{c}[76,77]$. Also, alike bafilomycins and concanamycins, for some time it was thought that binding to subunit a could also be part of its mechanism of action, but this hypothesis is now abandoned [78]. It was an attractive hypothesis because binding to this subunit could help explaining their unique preferential inhibition of osteoclast ATPases vs other mammalian VATPases $[74,75,79]$.

The synthesis and registration of all these compounds have fared different paths. No reports on the total synthesis of chondropsins are known to the authors to date. However, this or the difficulty in isolating this compounds from scarce natural sources have not been obstacles to register their use either alone or in conjunction with irradiation [80-82]. Archazolids are still in a preliminary stage and neither total synthesis or putative uses have been reported. Indoles, on their part, are fully synthetic molecules and, due to their apparent selectivity against osteoclast V-ATPases, they were 
first registered as putative treatment agents against osteoporosis [83]. Recently, it has been shown that they can also inhibit metastasis initiation and bone invasion in animal models [84, 85], and probably this has fueled the registration of this kind of compounds as anticancer agents [86].

\section{PERSPECTIVES AND FUTURE WORK}

So far, no cancer clinical trials with V-ATPase inhibitors are known, probably because of their high toxicity. This drawback stems from the high potency but lack of selectivity towards different tissues that most inhibitors show to date. Indoles could be considered and exception, but the small differences in affinity they show might not make them specific enough. In this sense, inhibition of V-ATPases in pancreas have been suggested to be linked to risk of induced glucose intolerance [87]. This is probably the most important issue to overcome before any compound inhibiting intracellular compartment acidification can reach the market. To this end, studies on different derivatives are paramount, specially those involving compounds already showing some kind of specificity. No doubt that these studies must come accompanied by structural studies on the mode of inhibition and binding site of these inhibitors. A fruitful approach can also be the simplification of compounds, as it was done with plecomacrolides rendering indoles and azaindoles. This can be specially important for compounds such as the chondropsins, which can be cumbersome to synthesize and difficult to obtain from natural sources. The search for new classes of compounds can also yield interesting results, as it is proven from the fact that several classes of totally unrelated compounds and tens of derivatives are already available since the discovery of bafilomycin A in 1988. With the availability of high throughput screening techniques, it can be expected that new compounds will come up soon. As it is, the interest in these compounds remains high as judged by the fair amount of patents issued. 


\section{ACKNOWLEDGMENTS}

The authors thank the Andalucian Regional Government and the Spanish Ministry of Science and Innovation for their support to PAIDI group BIO-261 through grants P07-CVI-3082 and BMC200761887 , respectively.

\section{REFERENCES}

[1] P.M. Kane, The where, when, and how of organelle acidification by the yeast vacuolar H+ATPase, Microbiol Mol Biol Rev 70 (2006) 177-191.

[2] O.A. Weisz, Acidification and protein traffic, Int Rev Cytol 226 (2003) 259-319.

[3] A. Rivinoja, A. Hassinen, N. Kokkonen, A. Kauppila, S. Kellokumpu, Elevated Golgi pH impairs terminal N-glycosylation by inducing mislocalization of Golgi glycosyltransferases, J Cell Physiol 220 (2009) 144-154.

[4] M.A. Axelsson, N.G. Karlsson, D.M. Steel, J. Ouwendijk, T. Nilsson, G.C. Hansson, Neutralization of $\mathrm{pH}$ in the Golgi apparatus causes redistribution of glycosyltransferases and changes in the O-glycosylation of mucins, Glycobiology 11 (2001) 633-644.

[5] S.R. Sennoune, K. Bakunts, G.M. Martínez, J.L. Chua-Tuan, Y. Kebir, M.N. Attaya, R. Martínez-Zaguilán, Vacuolar H+-ATPase in human breast cancer cells with distinct metastatic potential: distribution and functional activity, Am J Physiol Cell Physiol 286 (2004) C1443-1452.

[6] M. Forgac, Vacuolar ATPases: rotary proton pumps in physiology and pathophysiology, Nat Rev Mol Cell Biol 8 (2007) 917-929.

[7] Y.Y. Sautin, M. Lu, A. Gaugler, L. Zhang, S.L. Gluck, Phosphatidylinositol 3-kinasemediated effects of glucose on vacuolar H+-ATPase assembly, translocation, and acidification of intracellular compartments in renal epithelial cells, Mol Cell Biol 25 (2005) 
$575-589$.

[8] S. Breton, D. Brown, New insights into the regulation of V-ATPase-dependent proton secretion, Am J Physiol Renal Physiol 292 (2007) F1-10.

[9] M. Voss, O. Vitavska, B. Walz, H. Wieczorek, O. Baumann, Stimulus-induced phosphorylation of vacuolar $\mathrm{H}(+)$-ATPase by protein kinase A, J Biol Chem 282 (2007) $33735-33742$.

[10] V. Makrantoni, P. Dennison, M.J.R. Stark, P.J. Coote, A novel role for the yeast protein kinase Dbf2p in vacuolar $\mathrm{H}+$-ATPase function and sorbic acid stress tolerance, Microbiology 153 (2007) 4016-4026.

[11] K.R. Hallows, R. Alzamora, H. Li, F. Gong, C. Smolak, D. Neumann, N.M. Pastor-Soler, AMP-activated protein kinase inhibits alkaline $\mathrm{pH}-$ and $\mathrm{PKA}$-induced apical vacuolar $\mathrm{H}+-$ ATPase accumulation in epididymal clear cells, Am J Physiol Cell Physiol 296 (2009) C672-681.

[12] A. Hernández, G. López-Lluch, J.A. Bernal, P. Navas, J.A. Pintor-Toro, Dicoumarol downregulates human PTTG1/Securin mRNA expression through inhibition of Hsp90, Mol Cancer Ther 7 (2008) 474-482.

[13] S. Kubota, Y. Seyama, Overexpression of vacuolar ATPase 16-kDa subunit in 10T1/2 fibroblasts enhances invasion with concomitant induction of matrix metalloproteinase-2, Biochem Biophys Res Commun 278 (2000) 390-394.

[14] Y. Yoshimoto, M. Imoto, Induction of EGF-dependent apoptosis by vacuolar-type H(+)ATPase inhibitors in A431 cells overexpressing the EGF receptor, Exp Cell Res 279 (2002) 118-127.

[15] K. Aiko, T. Tsujisawa, T. Koseki, S. Hashimoto, Y. Morimoto, T. Amagasa, T. Nishihara, Involvement of cytochrome $\mathrm{c}$ and caspases in apoptotic cell death of human submandibular gland ductal cells induced by concanamycin A, Cell Signal 14 (2002) 717-722.

[16] A.W. van Weert, K.W. Dunn, H.J. Gueze, F.R. Maxfield, W. Stoorvogel, Transport from late 
endosomes to lysosomes, but not sorting of integral membrane proteins in endosomes, depends on the vacuolar proton pump, J Cell Biol 130 (1995) 821-834.

[17] H.A.J. Alwan, E.J.J. van Zoelen, J.E.M. van Leeuwen, Ligand-induced lysosomal epidermal growth factor receptor (EGFR) degradation is preceded by proteasome-dependent EGFR deubiquitination, J Biol Chem 278 (2003) 35781-35790.

[18] N. Perzov, H. Nelson, N. Nelson, Altered distribution of the yeast plasma membrane H+ATPase as a feature of vacuolar H+-ATPase null mutants, J Biol Chem 275 (2000) 4008840095 .

[19] L. Taupenot, K.L. Harper, D.T. O'Connor, Role of H+-ATPase-mediated acidification in sorting and release of the regulated secretory protein chromogranin A: evidence for a vesiculogenic function, J Biol Chem 280 (2005) 3885-3897.

[20] D.-H. Seog, SS33410, an inhibitor of V-ATPase, blocks intracellular protein transport of the VSV-G protein in the Golgi compartment, Biosci Biotechnol Biochem 67 (2003) 2591-2597.

[21] M.G. Vander Heiden, L.C. Cantley, C.B. Thompson, Understanding the Warburg effect: the metabolic requirements of cell proliferation, Science 324 (2009) 1029-1033.

[22] J.A. Joyce, D. Hanahan, Multiple roles for cysteine cathepsins in cancer, Cell Cycle 3 (2004) 1516-1619.

[23] D. Lagadic-Gossmann, L. Huc, V. Lecureur, Alterations of intracellular pH homeostasis in apoptosis: origins and roles, Cell Death Differ 11 (2004) 953-961.

[24] S. Simon, D. Roy, M. Schindler, Intracellular $\mathrm{pH}$ and the control of multidrug resistance, Proc Natl Acad Sci U S A 91 (1994) 1128-1132-1128-1132.

[25] V.Y. Chen, G.R. Rosania, The Great Multidrug-Resistance Paradox, ACS Chem Biol 1 (2006) 271-273.

[26] C. Millot, J.-M. Millot, H. Morjani, A. Desplaces, M. Manfait, Characterization of Acidic Vesicles in Multidrug-resistant and Sensitive Cancer Cells by Acridine Orange Staining and Confocal Microspectrofluorometry, J Histochem Cytochem 45 (1997) 1255-1264. 
[27] K.H. Weylandt, M. Nebrig, N. Jansen-Rosseck, J.S. Amey, D. Carmena, B. Wiedenmann, C.F. Higgins, A. Sardini, ClC-3 expression enhances etoposide resistance by increasing acidification of the late endocytic compartment, Mol Cancer Ther 6 (2007) 979-986.

[28] W. Castillo-Avila, M. Abal, S. Robine, R. Pérez-Tomás, Non-apoptotic concentrations of prodigiosin $(\mathrm{H}+/ \mathrm{Cl}-$ symporter) inhibit the acidification of lysosomes and induce cell cycle blockage in colon cancer cells, Life Sciences 78 (2005) 121-127.

[29] A. De Milito, E. Iessi, M. Logozzi, F. Lozupone, M. Spada, M.L. Marino, C. Federici, M. Perdicchio, P. Matarrese, L. Lugini, A. Nilsson, S. Fais, Proton pump inhibitors induce apoptosis of human B-cell tumors through a caspase-independent mechanism involving reactive oxygen species, Cancer Res 67 (2007) 5408-5417.

[30] C. Chevallier, O. Laprévote, J. Bignon, C. Debitus, D. Guénard, T. Sévenet, Isolation of cytotoxic chondropsins, macrolide lactams from the New-Caledonian marine sponge Psammoclemma sp. and electrospray ion trap multiple stage MS study of these macrolides, Nat Prod Res 18 (2004) 479-484.

[31] J. Hong, A. Yokomakura, Y. Nakano, K. Ishihara, M. Kaneda, M. Onodera, K.-i. Nakahama, I. Morita, K. Niikura, J.-W. Ahn, O. Zee, K. Ohuchi, Inhibition of vacuolar-type (H+)ATPase by the cytostatic macrolide apicularen A and its role in apicularen A-induced apoptosis in RAW 264.7 cells, FEBS Lett 580 (2006) 2723-2730.

[32] T. Morimura, K. Fujita, M. Akita, M. Nagashima, A. Satomi, The proton pump inhibitor inhibits cell growth and induces apoptosis in human hepatoblastoma, Pediatr Surg Int 24 (2008) 1087-1094.

[33] J. Xu, H.T. Feng, C. Wang, K.H.M. Yip, N. Pavlos, J.M. Papadimitriou, D. Wood, M.H. Zheng, Effects of Bafilomycin A1: an inhibitor of vacuolar $\mathrm{H}(+)$-ATPases on endocytosis and apoptosis in RAW cells and RAW cell-derived osteoclasts, J Cell Biochem 88 (2003) $1256-1264$.

[34] X. Huang, A. Masselli, S.M. Frisch, I.C. Hunton, Y. Jiang, J.Y.J. Wang, Blockade of tumor 
necrosis factor-induced Bid cleavage by caspase-resistant Rb, J Biol Chem 282 (2007) 29401-29413.

[35] Y. Sasazawa, Y. Futamura, E. Tashiro, M. Imoto, Vacuolar H(+)-ATPase inhibitors overcome Bcl-xL-mediated chemoresistance through restoration of a caspase-independent apoptotic pathway, Cancer Sci 100 (2009) 1460-1467.

[36] J. Hong, K. Yamaki, K. Ishihara, J.W. Ahn, O. Zee, K. Ohuchi, Induction of apoptosis of RAW 264.7 cells by the cytostatic macrolide apicularen A, J Pharm Pharmacol 55 (2003) 1299-1306.

[37] M. Kawada, I. Usami, S. Ohba, T. Someno, J. Kim, Y. Hayakawa, K. Nose, M. Ishizuka, Hygrolidin induces p21 expression and abrogates cell cycle progression at G1 and S phases, Biochem Biophys Res Commun 298 (2002) 178-183.

[38] J.-H. Lim, J.-W. Park, M.-S. Kim, S.-K. Park, R.S. Johnson, Y.-S. Chun, Bafilomycin induces the p21-mediated growth inhibition of cancer cells under hypoxic conditions by expressing hypoxia-inducible factor-1alpha, Mol Pharmacol 70 (2006) 1856-1865.

[39] M. Koshiji, L.E. Huang, Dynamic balancing of the dual nature of HIF-1alpha for cell survival, Cell Cycle 3 (2004) 853-854.

[40] E.J. Bowman, A. Siebers, K. Altendorf, Bafilomycins: a class of inhibitors of membrane ATPases from microorganisms, animal cells, and plant cells, Proc Natl Acad Sci U S A 85 (1988) 7972-7976.

[41] S. Dröse, K.U. Bindseil, E.J. Bowman, A. Siebers, A. Zeeck, K. Altendorf, Inhibitory effect of modified bafilomycins and concanamycins on P- and V-type adenosinetriphosphatases, Biochemistry 32 (1993) 3902-3906.

[42] M. Huss, H. Wieczorek, Inhibitors of V-ATPases: old and new players, J Exp Biol 212 (2009) 341-346.

[43] J. Zhang, Y. Feng, M. Forgac, Proton conduction and bafilomycin binding by the V0 domain of the coated vesicle V-ATPase, J Biol Chem 269 (1994) 23518-23523. 
[44] Y. Wang, T. Inoue, M. Forgac, Subunit a of the yeast V-ATPase participates in binding of bafilomycin, J Biol Chem 280 (2005) 40481-40488.

[45] M. Huss, G. Ingenhorst, S. Konig, M. Gassel, S. Drose, A. Zeeck, K. Altendorf, H. Wieczorek, Concanamycin A, the Specific Inhibitor of V-ATPases, Binds to the Vo Subunit c, J Biol Chem 277 (2002) 40544-40548.

[46] J. Hong, Y. Nakano, A. Yokomakura, K. Ishihara, S. Kim, Y.-S. Kang, K. Ohuchi, Nitric oxide production by the vacuolar-type $(\mathrm{H}+)$-ATPase inhibitors bafilomycin A1 and concanamycin A and its possible role in apoptosis in RAW 264.7 cells, J Pharmacol Exp Ther 319 (2006) 672-681.

[47] V.V. Teplova, A.A. Tonshin, P.A. Grigoriev, N.-E.L. Saris, M.S. Salkinoja-Salonen, Bafilomycin A1 is a potassium ionophore that impairs mitochondrial functions, J Bioenerg Biomembr 39 (2007) 321-329.

[48] K. Toshima, T. Jyojima, H. Yamaguchi, Y. Noguchi, T. Yoshida, H. Murase, M. Nakata, S. Matsumura, Total Synthesis of Bafilomycin A(1), J Org Chem 62 (1997) 3271-3284.

[49] K. Toshima, T. Jyojima, N. Miyamoto, M. Katohno, M. Nakata, S. Matsumura, The first total synthesis of concanamycin f (concanolide a), J Org Chem 66 (2001) 1708-1715.

[50] T.G. Holt, R.L. Monaghan: US19945306716 (1994).

[51] S. Paglin, J. Yahalom, T. Hollister, T. Delohery: US20066982252 (2006).

[52] C. Khosla, A. Salomon: US20056974664 (2005).

[53] C. Khosla, A. Fujie: US20036548485 (2003).

[54] A.R. Salomon, D.W. Voehringer, L.A. Herzenberg, C. Khosla, Apoptolidin, a selective cytotoxic agent, is an inhibitor of F0F1-ATPase, Chem Biol 8 (2001) 71-80.

[55] P.A. Wender, O.D. Jankowski, E.A. Tabet: US20067151116 (2006).

[56] K. Erickson, J. Beutler, J. Cardellina Ii, M. Boyd, Salicylihalamides A and B, Novel Cytotoxic Macrolides from the Marine Sponge Haliclona sp, J Org Chem 62 (1997) 81888192. 
[57] D.L. Galinis, T.C. McKee, L.K. Pannell, J.H. Cardellina, M.R. Boyd, Lobatamides A and B, Novel Cytotoxic Macrolides from the Tunicate Aplidium lobatum, J Org Chem 62 (1997) 8968-8969.

[58] B. Kunze, R. Jansen, F. Sasse, G. Höfle, H. Reichenbach, Apicularens A and B, new cytostatic macrolides from Chondromyces species (myxobacteria): production, physicochemical and biological properties, J Antibiot 51 (1998) 1075-1080.

[59] M.R. Boyd, C. Farina, P. Belfiore, S. Gagliardi, J.W. Kim, Y. Hayakawa, J.A. Beutler, T.C. McKee, B.J. Bowman, E.J. Bowman, Discovery of a novel antitumor benzolactone enamide class that selectively inhibits mammalian vacuolar-type (H+)-atpases, J Pharmacol Exp Ther 297 (2001) 114-120.

[60] X.-S. Xie, D. Padron, X. Liao, J. Wang, M.G. Roth, J.K. De Brabander, Salicylihalamide A inhibits the V0 sector of the V-ATPase through a mechanism distinct from bafilomycin A1, J Biol Chem 279 (2004) 19755-19763.

[61] M. Huss, F. Sasse, B. Kunze, R. Jansen, H. Steinmetz, G. Ingenhorst, A. Zeeck, H. Wieczorek, Archazolid and apicularen: novel specific V-ATPase inhibitors, BMC Biochem 6 (2005) 13-13.

[62] Y. Wu, O.R. Seguil, J.K. De Brabander, Synthesis and initial structure--activity relationships of modified salicylihalamides, Org Lett 2 (2000) 4241-4244.

[63] R. Shen, C.T. Lin, J.A. Porco, Total synthesis and stereochemical assignment of the salicylate antitumor macrolide lobatamide C(1), J Am Chem Soc 124 (2002) 5650-5651.

[64] A. Lewis, I. Stefanuti, S.A. Swain, S.A. Smith, R.J. Taylor, A formal total synthesis of (+)apicularen A: base-induced conversion of apicularen-derived intermediates into salicylihalamide-like products, Org Biomol Chem 1 (2003) 104-116.

[65] J.K. De Brabander, Y. Wu: US20036617348 (2003).

[66] J. De Brabander, Y. Wu: US20046734209 (2004).

[67] J. De Brabander, Y. Wu: US20056936723 (2005). 
[68] M.R. Boyd: US20080275108 (2008).

[69] J.K. De Brabander, X. Jiang, B. Liu: US20080249162 (2008).

[70] C.L. Cantrell, K.R. Gustafson, M.R. Cecere, L.K. Pannell, M.R. Boyd, Chondropsins A and B: Novel Tumor Cell Growth-Inhibitory Macrolide Lactams from the Marine Sponge Chondropsis sp, J Am Chem Soc 122 (2000) 8825-8829.

[71] M.A. Rashid, C.L. Cantrell, K.R. Gustafson, M.R. Boyd, Chondropsin D, a new $37-$ membered-ring macrolide lactam from the marine sponge Chondropsis species, J Nat Prod 64 (2001) 1341-1344.

[72] E.J. Bowman, K.R. Gustafson, B.J. Bowman, M.R. Boyd, Identification of a new chondropsin class of antitumor compound that selectively inhibits V-ATPases, J Biol Chem 278 (2003) 44147-44152.

[73] F. Sasse, H. Steinmetz, G. Höfle, H. Reichenbach, Archazolids, new cytotoxic macrolactones from Archangium gephyra (Myxobacteria). Production, isolation, physicochemical and biological properties, J Antibiot 56 (2003) 520-525.

[74] S. Gagliardi, G. Nadler, E. Consolandi, C. Parini, M. Morvan, M.N. Legave, P. Belfiore, A. Zocchetti, G.D. Clarke, I. James, P. Nambi, M. Gowen, C. Farina, 5-(5,6-Dichloro-2indolyl)-2-methoxy-2,4-pentadienamides: novel and selective inhibitors of the vacuolar H+ATPase of osteoclasts with bone antiresorptive activity, J Med Chem 41 (1998) 1568-1573.

[75] G. Nadler, M. Morvan, I. Delimoge, P. Belfiore, A. Zocchetti, I. James, D. Zembryki, E. Lee-Rycakzewski, C. Parini, E. Consolandi, S. Gagliardi, C. Farina, (2Z,4E)-5-(5,6dichloro-2-indolyl)-2-methoxy-N-(1,2,2,6,6- pentamethylpiperidin-4-yl)-2,4pentadienamide, a novel, potent and selective inhibitor of the osteoclast V-ATPase, Bioorg Med Chem Lett 8 (1998) 3621-3626.

[76] G. Whyteside, P.J. Meek, S.K. Ball, N. Dixon, M.E. Finbow, T.P. Kee, J.B.C. Findlay, M.A. Harrison, Concanamycin and Indolyl Pentadieneamide Inhibitors of the Vacuolar H+ATPase Bind with High Affinity to the Purified Proteolipid Subunit of the Membrane 
Domain, Biochemistry 44 (2005) 15024-15031.

[77] T. Páli, N. Dixon, T.P. Kee, D. Marsh, Incorporation of the V-ATPase inhibitors concanamycin and indole pentadiene in lipid membranes. Spin-label EPR studies, Biochim Biophys Acta 1663 (2004) 14-18.

[78] R.W. Hesselink, A. Fedorov, M.A. Hemminga, M. Prieto, Membrane-bound peptides from V-ATPase subunit a do not interact with an indole-type inhibitor, J Pept Sci 14 (2008) 383388.

[79] C. Farina, S. Gagliardi, G. Nadler, M. Morvan, C. Parini, P. Belfiore, L. Visentin, M. Gowen, Novel bone antiresorptive agents that selectively inhibit the osteoclast V-H+ATPase, Farmaco 56 (2001) 113-116.

[80] M.R. Boyd, K.R. Gustafson, C.L. Cantrell: US20067144918 (2006).

[81] M.R. Boyd, K.R. Gustafson: US20077205334 (2007).

[82] M.R. Boyd, K.R. Gustafson: US20097521475 (2009).

[83] C. Farina, S. Gagliardi, G.M.M.G. Nadler: US20056903117 (2005).

[84] K. Niikura, Effect of a V-ATPase inhibitor, FR202126, in syngeneic mouse model of experimental bone metastasis, Cancer Chemother Pharmacol 60 (2007) 555-562.

[85] R. Supino, G. Petrangolini, G. Pratesi, M. Tortoreto, E. Favini, L.D. Bo, P. Casalini, E. Radaelli, A.C. Croce, G. Bottiroli, P. Misiano, C. Farina, F. Zunino, Antimetastatic effect of a small-molecule vacuolar $\mathrm{H}+-$ ATPase inhibitor in in vitro and in vivo preclinical studies, $\mathrm{J}$ Pharmacol Exp Ther 324 (2008) 15-22.

[86] C. Farina, S. Gagliardi, P. Misiano, P. Celestini, F. Zunino: US20070248672 (2007).

[87] K.D. Hettiarachchi, P.Z. Zimmet, M.A. Myers, The effects of repeated exposure to sub-toxic doses of plecomacrolide antibiotics on the endocrine pancreas, Food Chem Tox 44 (2006) 1966-1977. 


\section{Figure legends}

Fig.(1). Traffic between intracellular compartments and their characteristic $p H$. Vesicle flux between single membrane organelles is shown by arrows.

Fig.(2). Subunit structure of V-ATPases. Subunits A to F constitute the hydrophilic $\mathrm{V}_{1}$ domain; subunits a to e comprise the $\mathrm{V}_{0}$ membrane-embedded domain.

Fig. (3). Structure of some plecomacrolides. A, bafilomycin A; B, concanamycin A.

Fig.(4). Examples of benzolactone enamides. A, salicylihalimide A; B, lobatimide A; C, apicularen A.

Fig.(5). Other diverse V-ATPase inhibitors. A, chondropsin A; B, Archazolid A; C, NiK12192 (indole). 
Figure 1

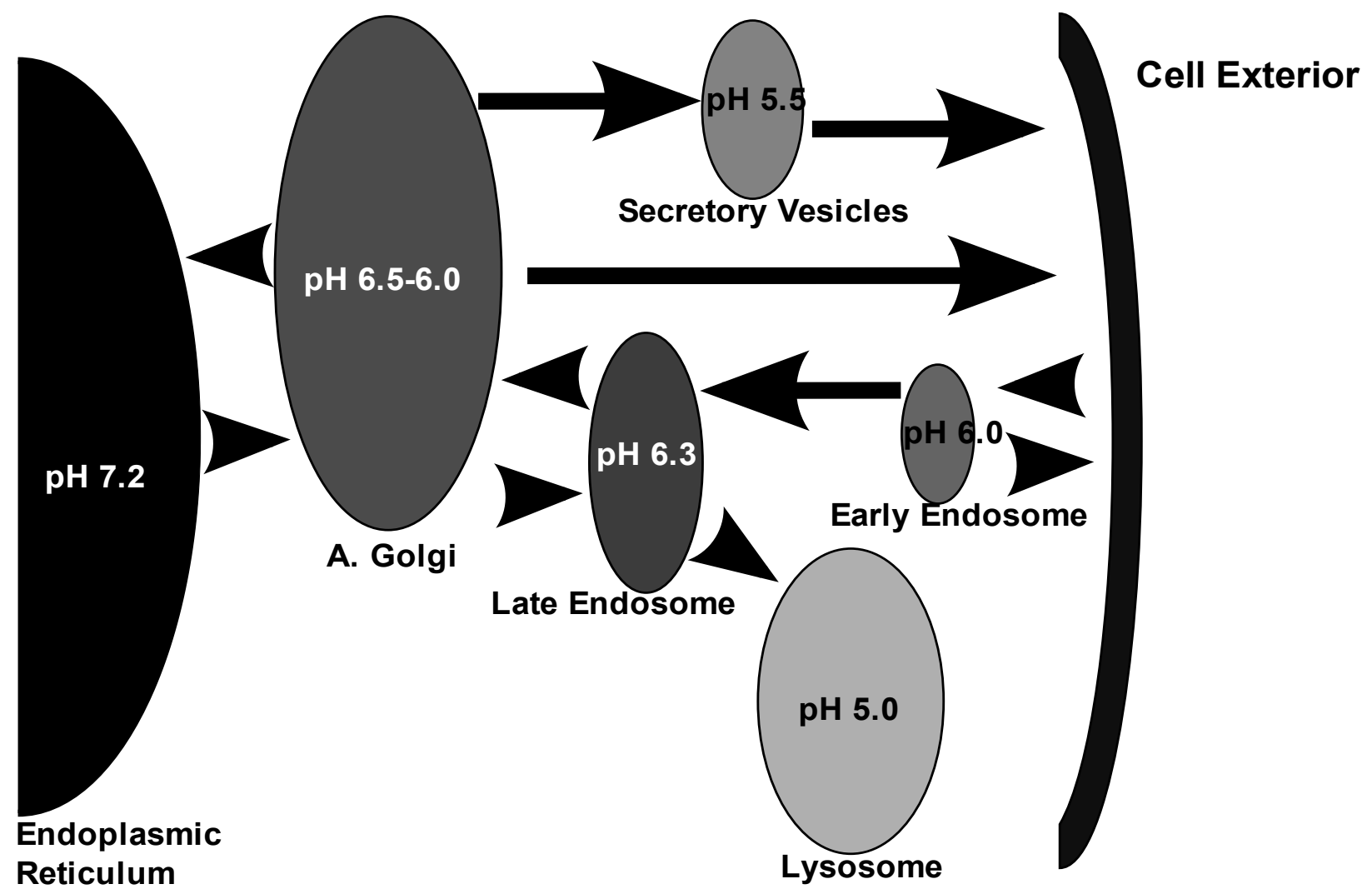


Figure 2

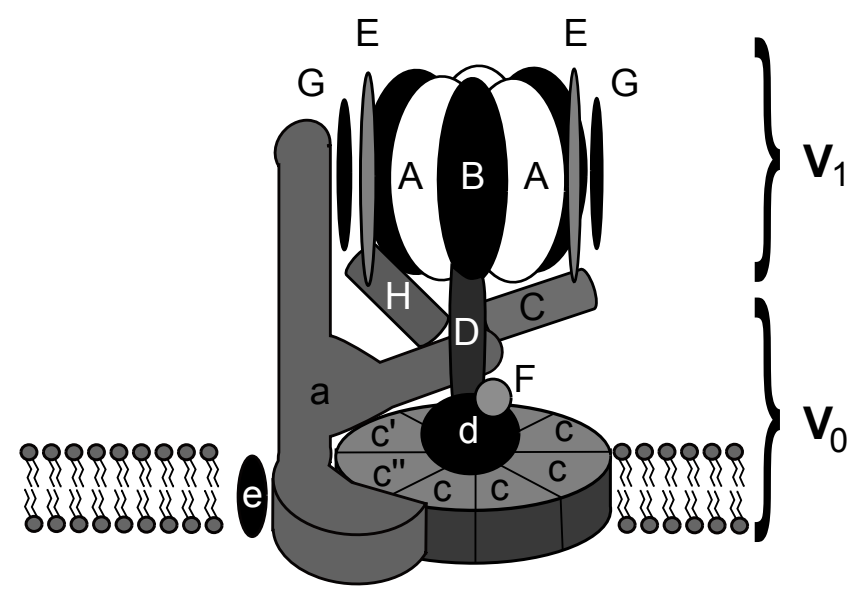


Figure 3

A<smiles>CC1=CC(=O)OC(C(C)C(O)C(C)C2(O)CC(O)C(C)C(C(C)C)O2)C(C)CC(C)=CC(C)C(O)C(C)CC(C)=C1</smiles>

B

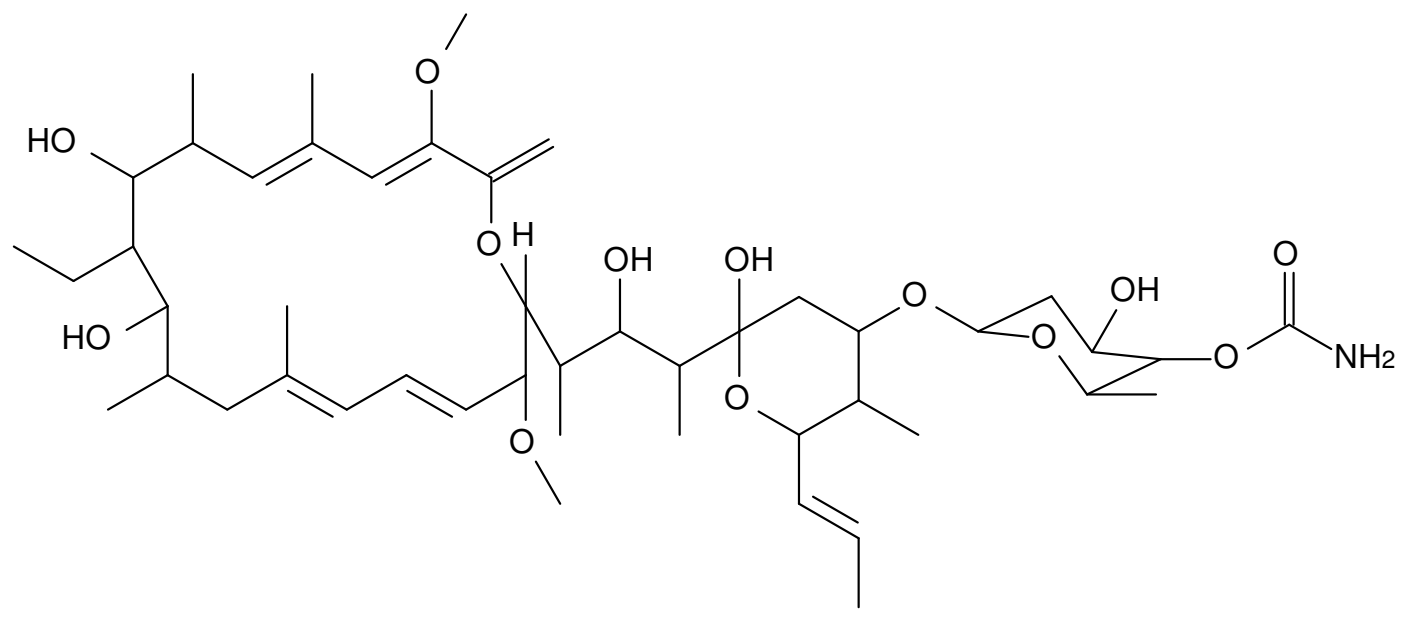


Figure 4

A<smiles>CC/C=C\C=C/C(=O)N/C=C/CC1CC(O)CC/C=C/Cc2cccc(O)c2C(=O)O1</smiles>

B<smiles>C/C=C\C(O)/C(C)=C/Cc1cccc(O)c1C(=O)OC(C/C=C\NC(=O)/C=C/C=N/OC)CC(=O)OCC</smiles>

C<smiles>CC/C=C\C=C/C(=O)N/C=C/CC1CC2CC(O)CC(Cc3cccc(O)c3C(=O)O1)O2</smiles> 
Figure 5

A
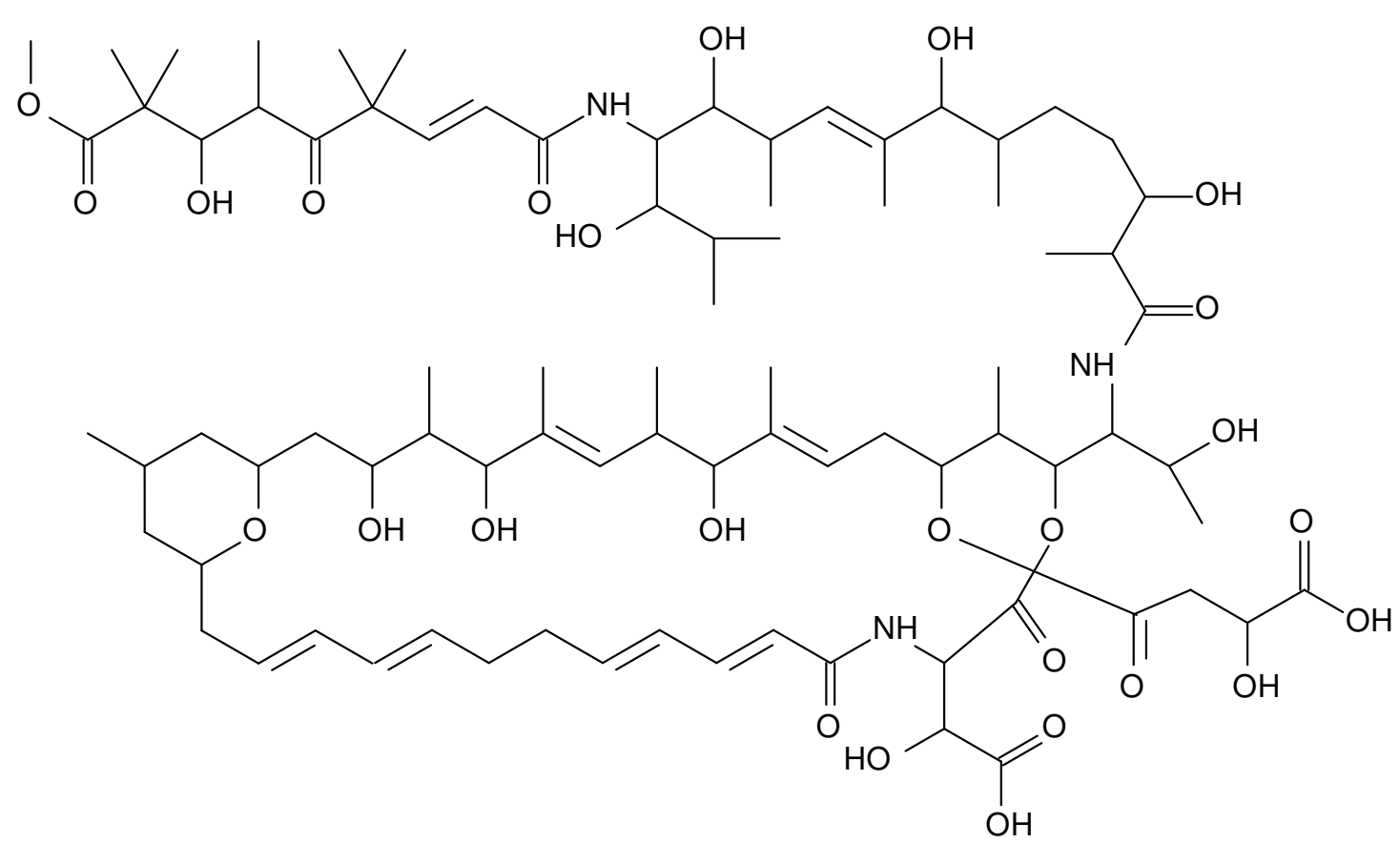

B

C

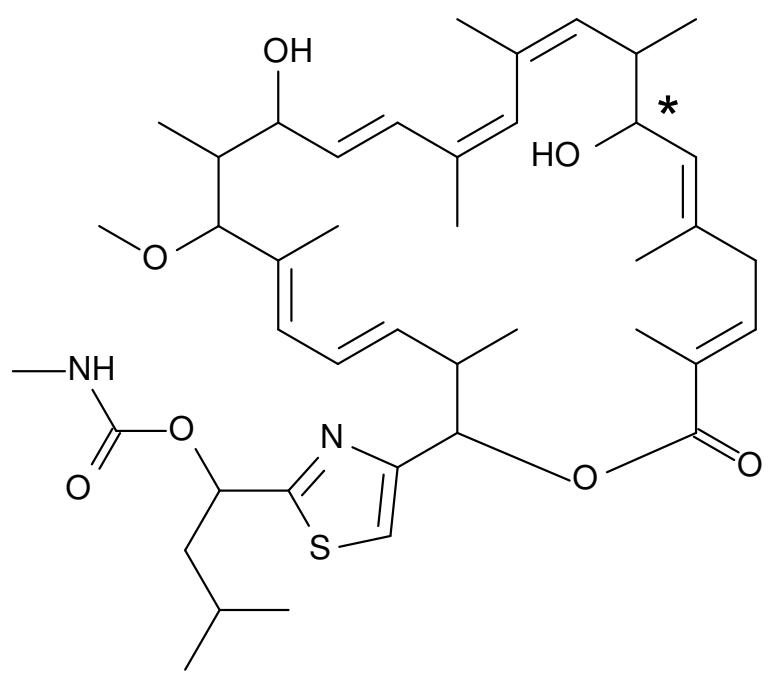

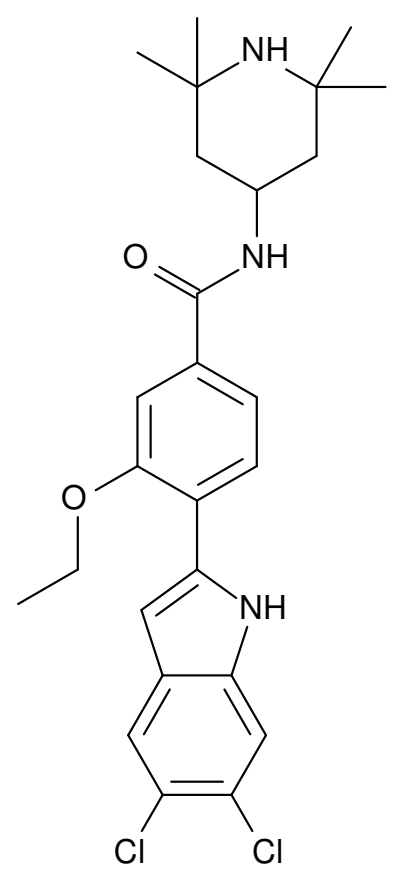

